\title{
Inclusive Health-Care: The Best Raw Material for Progressive and Inclusive Growth in India
}

\author{
Jyoti Kumari Sharma ${ }^{1 *}$ and Anil Bhumali ${ }^{2}$ \\ ${ }^{I}$ Department of Economics, Balurghat College, West Bengal, India \\ ${ }^{2}$ Vice-Chancellor, Raiganj University, West Bengal, India \\ *Corresponding author: jyotikumaris@yahoo.com
}

\begin{abstract}
Inclusive Growth has taken into account of economic growth heading towards equitable allocation of resources with benefits rendered to every section of society, leading to sustainable economic development as a whole. It addresses the basic interrelated issues like education, health, employment, rural-urban infrastructure and financial inclusion. Under these elements inclusive growth allows people to "contribute to" and "benefit from", economic growth on the whole on equitable terms.

Of these elements health-care is considered as the most important element through which citizens are formalized to the basic social security health measures, with quality management, patient safety, efficiency and appropriateness of care. In this way inclusive health-care facilities helps the citizens of the concerned country to act as the raw material to learn, examine, analyze and implement the policies needed for economic development of the country, in a best possible way.

We know that the contribution to the health of a population derives from basic three social determinants of living, which are as follows:

(a) Living conditions with respect to nutritious food, safe drinking water and sanitation facilities.

(b) Well maintained health facilities with respect to development of hospitals pharmaceutical facilities.

(c) Reliable logistics, healthcare delivery strategies of hospitals quality medicine and technological health-care facilities.

Thus, the Government of India needs to improve Quality, Efficiency and Equity by providing the best health-care facilities to all, with improvement in the economic reforms of India heading towards progressive economic growth with strong equality. This paper discusses in detail the concept of inclusive health-care, including its importance, challenges and measures to implement inclusive health-care in India, to usher in attaining inclusive growth in India.
\end{abstract}

Keywords: Economic growth, education, health, employment, Equity, health-care 
Health care refers to both necessary and preventive human efforts made to improve their physical and mental well-being. It is done by following the procedures of diagnosis, treatment $\&$ prevention of disease, illness, injury and other physical-mental impairments in human beings. The Healthcare system is an organization established in the country to meet the health needs of people living there, which are the citizens along with the foreigners. This system entity varies under their exact configuration settings followed by their service-delivery though at national and sub national level.

In all cases, according to the World Health Organisation (WHO), a well- functioning healthcare system requires following:

1. A robust financing mechanism.

2. A well trained and adequately-paid workforce.

3. Reliable information on which decisions and policies can be made and

4. Well maintained health facilities along with its logistics, to deliver quality medicines and technologies.

So, on this basis, among the above mentioned features of inclusive growth under health care system, we know that to make that economic development more inclusive, it requires better HEALTH CAREcoverage and quality. This can be checked and analyzed on the basis of the parameters like birth rate, death rate, total fertility rate, maternal mortality rate, infant mortality rate and life expectancy at birth. There raises a concept of INCLUSIVE HEALTH-CARE, as for all these development, we need a healthy human resource in the country, which is possible only through inclusive health care facilities.

\section{INCLUSIVE HEALTH-CARE}

Inclusive health care is a new development strategy started under the objectives of inclusive growth. Thus, INCLUSIVE HEALTH-CARE is defined as a development strategy, which aims at making health care services and facilities, at least in terms primary health care services universally accessible and affordable to all, including poor, vulnerable and socially marginalized groups of the society, on an equity basis.

In these terms, this strategy is heading towards "HEALTH FOR ALL", which aims to attain health as a part of overall development with its core value of equity, starting with primary health care based on "acceptable methods and technology". It is made universally accessible to all individuals and families in the community through their full participation and at a cost that it can be afforded with respect to the health care needed and made available in the country.

$\square$ Under this strategy, according to the supporter of inclusion, the practise of developing inclusive health-care services, followed by development of its institutions involves following:

$\square$ Understanding health-care inclusion as a continuous process and not a one-time event or happening.

$\square$ Strengthening and sustaining the participation of all health-care institutions, its staffs, community members and pharmacies in the work of inclusive health-care systems.

$\square$ Restructuring the societal values, cultures, policies and practices both within an inclusive healthcare institution as well as outside to respond to the diversity of patients health-care demand in a given locality.

$\square$ Providing an appropriate and accessible curriculum with appropriate training programmes of 
full information, environments and support. It is made for all health-care institutions, its staffs, community members and pharmacies.

$\square$ Accordingly, for Identifying and providing support to staff as well as patients with the view to make inclusion in health-care systems a success, the following factors are to be considered:

$\square$ Health-care institutions, its staffs, community members and pharmacies partnerships.

$\square$ Collaboration between general and special health care institutions, its staffs and pharmacies.

$\square$ Well-constructed individualized health-care programme and plans.

$\square$ Team planning and communication, followed by Integration of health-care service with respect to its delivery.

$\square$ Ongoing training and staff development.

Under this concept of inclusive growth followed by health care facilities, that include inclusive health care policies build on an equity basis, promises to prioritise to attain health care to all including vulnerable and socially marginalized groups of the society. This is taken as a very important part of overall development of the country with respect to the health-care system under it, motivating the all human resources of the concerned country, to work for the country's progressive and positive economic growth with efficiency under a healthy-life, following motives of equity.

\section{Types of Inclusive Health-Care Services}

Role of health-care in economic development is analyzed via two channels:

$\square$-The direct labour productivity effect.

$\square$-The indirect incentive effect.

Under which inclusive health care is now categorised into three sub-types:

(a) Inclusive Primary Health-Care Services: Primary health care services refer to the work of health professionals who act as a $1^{\text {st }}$ point of consultation for all patients within the health care system. Such a professional would usually be:

○ Primary care physician- Such as a general physician or practitioner.

$\odot$ Licensed independent practitioner- Such as physiotherapists.

$\odot \quad$ Non-physician primary care provider- They are mid-level provider, such as physician assistant or nurse practitioner.

When for providing all these primary healthcare services there is no discrimination and is provided on inclusive terms, even including the poor and disadvantaged sections of the society, it becomes Inclusive Primary Health-Care Services.

(b) Inclusive Secondary Health-Care Services: Secondary health care includes acute health care, that is necessary treatment for a short period of time for a brief but in a hospital emergency department such as serious illness, injury or other health condition. However, many secondary healthcare suppliers do not essentially work in hospital like psychiatrists, psychologists, clinical activity therapists, most dental specialties, physiotherapists etc. When for all these secondary 
health-care services there is no discrimination and is provided on inclusive terms, even including the poor and disadvantaged sections of the society, it becomes Inclusive Secondary Health-Care Services.

(c) Inclusive Tertisary Health-Care Services: Tertiary health-care is those healthcare service sector referral hospitals, clinics etc which is specialized in health care consulting. They function usually for both inpatients and on referral from professional of primary or secondary health care. This is done with the facility that has both personal and advanced medical investigations with treatment in these tertiary referral hospitals. Examples of Tertiary health-care services are cancer management, cardiac surgery, neurosurgery, plastic surgery etc. When for all these tertiary healthcare services there is no discrimination and is provided on inclusive terms, even including the poor and disadvantaged sections of the society, it becomes Inclusive Tertiary Health-Care Services.

So, accordingly Healthcare systems involve the function related to strengthening human resources development along with capacity building and regulation in the public health-care centre, as an important area within the HEALTH-DEVELOPMENT sectors.

But under the implementation of inclusive-health care facilities in all these types of the health-care system, there are always few problems seen in the Indian health-care system like:

$\square$ Unequal distribution of health-care services,

$\square$ Communicable diseases,

Poor-management,

Privatisation-competition,

$\square$ Poor maintenance of health-care centres etc.

Thus, inclusive approach focuses on identifying and reducing the barriers to learning along with participation related to it. At the same time it focuses on the special full information with respect to the curing of diseases and answering the needs of all individual or group of patients. So, accordingly how inclusive health-care targets services to address the needs and problems of inclusion in the field of healthcare can be analysed through the history of its start, implementation and progress around the world.

\section{Health-Care System of India}

Since ancient period of time, hospitals existed in India. In the $6^{\text {th }}$ century BC (during the time of Buddha), there were a number of hospitals which looked after the handicapped and the poor people of India. In period between 273-232 BC, the first outstanding hospital in India was built by king Ashoka.

The invasion of foreigner in $10^{\text {th }}$ century AD brought with them their own physicians called hakims. In the $16^{\text {th }}$ century with the arrival of European missionaries, the use of the allopathetic system of medicine commenced. It was also during the British rule that there was progress in the construction of hospital, organized medical training started in $19^{\text {th }}$ century in India. 
This development of medical health care in India can be analyzed in detail as follows:

$\square$ Vedic Period: Indus valley culture was so developed that it assimilated the Aryan culture, although the Aryans brought their own gods and medical knowledge.

The chief source of knowledge of Aryan culture and medicine are the four Vedas.
$\odot \quad$ Rig Veda.
$\odot$ Sama Veda.
$\odot$ Yajnsa Veda.
$\odot$ Athena Veda.

These all were based on mental and physical ingredient of positive health with respect to human and prayers to free the world from disease and with an aim that everybody should have a healthy mind.

Traditional medicine is based on Ayurveda. Danvantri is called the patron god of Indian medicine, who initiated many methods of healing and passed it to sushruta, who was the celebrated surgeon and chakra, a court physician of King Kanishka of this time.

The Buddhist Period: Lord Buddha himself took very keen interest in supporting the science of medicine. Lord Buddha used to attend to sick himself. During the course of his travel for propagating Buddhism care of sick and medical education was given special attention.

$\square$ Post-Buddha and Muslim Period: Emperor Ashoka established many hospitals throughout the country onward, middle east physician in Umami system created their impact. Emperor Akbar (1555-1605), during his period encouraged the amalgamation of Umami and Ayurveda system.

$\square$ Christianity and Medical Care Period: Hospital became an integrated part of church of monasteries. Medicine was treated as religious practice and all missionaries with trained nuns and monks for medical treatment knowledge were present to take care of the sick.

During 1300-1800, the knowledge of medicine was broadened, but still health-care facilities in Indian hospital did not reach a high standard, till the middle of the $19^{\text {th }}$ century. It was because of crowding and infection prevalent in hospital.

$\square$ Mordern Period of Medicine: Between 1510 and 1515, in Goa, Portuguese founded the royal hospital and later basic-general medical training programmes was introduced by the Jesuits at Indian hospital, which was converted into a school of medicine and surgery in 1842.

French $1^{\text {st }}$ brought modern medicine to India in 1664 and British in 1668 . The $1^{\text {st }}$ medical school was started in Calcutta, followed by Madras in 1846. In 1943, the govt. of India appointed a committee called health survey and development committee headed by Sir Joseph Bhore and having nineteen other members. Before 1947, that is the pre-independence period of India depicted only authentic record of hospital development and health care system in India. Under which the govt. took steps, as important landmarks following history of Indian health administration, with respect to importance of environmental hygiene. They are as follows:

In 1859 , the appointment of royal commission took place, to enquire into the health of the Indian army. 
There were two reports of plaque commission, which was in 1896 followed by next in 1904 .

In 1919 , the $1^{\text {st }}$ health-reform was introduced by the government of India.

In 1935 , the $2^{\text {nd }}$ health-reform was introduced by the government of India.

\section{Policies and Programmes of Healthcare Implemented in India}

Under this analysis, it is seen that even in past-historical period of India, health programmes contributed directly to socio-economic growth of India. Therefore the government of India is giving due attention to health care in its five year plans. On this basis of this, since 1950 there has been a progressive increase in the outlay of these health plans since till now, which can be analyzed in details through policies, programmes and statistical status of health care in India.

Under this, India has famous health policies for reducing providing special health-care services to all Indians, especially related to reduction of disability problem. These are as follows:

$\square$ In 1955, the National Leprosy Eradication Programme (NLEP) was launched, to strengthen disability prevention and medical rehabilitation of persons affected by leprosy.

In the 1976, a centrally sponsored scheme named National Programme for Control of Blindness and Visual Impairment (NPCBVI) was launched, for the prevalence of blindness to $0.3 \%$ by 2020 , by providing high quality comprehensive eye-care in all medical sectors of India.

In 1982, the National Mental Health Programme (NMHP) was launched, to promote and encourage community participation in mental healthcare service development along with stimulating efforts towards self-help in the community.

In August 1992, Ministry of Health and Family Welfare of India launched National Iodine Deficiency Disorders Control Programme (NIDDCP), on the recommendation of central council of health to iodise the entire edible salt in the country and safe the Indian from iodine deficiency disorders like mental-physical retardation, cretinism, stillbirths, abortions etc.

$\square$ In the year 2002, Government of India as a central agency launched National Vectors-Borne Disease Control Programme (NVBDCP), to prevent and control six vector-borne diseases that are malaria, dengue, lymphatic filariasis, kala-azar, Japanese encephalitis and chikunguya in India.

$\square$ On $12^{\text {th }}$ April, 2005, Ministry of Health and Family Welfare of India launched National Rural Health Mission (NRHM), with an initiative to address the health needs of under-served rural areas, with the help of wide range, simultaneous actions, taking into consideration determinants of health such as clean water supply, sanitation, health-education, nutrition, social and gender equality for health services at all levels.

$\square$ On $12^{\text {th }}$ April, 2005, Prime Minister: Manmohan Singh launched Janani Suraksha Yojana (JSY), as a safe motherhood intervention under NRHM, with the objective of reducing maternal and neo-natal mortality, by promotion of institutional delivery among the poor pregnant women. It is a $100 \%$ centrally sponsored scheme implemented in all states, which integrates cash assistance with delivery and post-delivery care.

$\square$ In January 2007, Ministry of Health and Family Welfare with the support of the Directorate of Health services implemented, National Programme for Prevention and Control of Deafness 
(NPPCD), to prevent avoidable hearing loss on account of disease or injury and to develop institutional capacity for ear-care services by providing support for equipment, material and training support. Thus, in this way to reduce the total disease burden of deafness by $25 \%$ of existing burden by the end of $12^{\text {th }}$ five-year plan.

In 2007-08, under the $11^{\text {th }}$ five-year plan National Tobacco Control Programme (NTCP) was launched, in order to protect the youth and masses from the adverse effects of tobacco use, second hand smoke and to discourage the consumption of tobacco.

$\square$ In the 2008-09, under the $11^{\text {th }}$ five-year plan the government of India launched a National Programme for Prevention and control of Fluorosis (NPPCF), to prevent and control fluorosis through health-education, management including supplementation, survey etc.

$\square$ In September 2009, Union Health Minister: Gulam Nabi Azad launched the programme Navjat Sishu Suraksha Karyakaram (NSSK), to reduce the infant mortality rate from 55 to 30 by the year 2012.

$\square$ In the year 2010, Government of India launched a National Programme for prevention and control of Cancer, Diabetes, Cardiovascular diseases and Stroke (NPCDCS), to prevent and control these non communicable diseases mentioned in its name. The main focus of this programme was on health promotion, early identification, management and referral of cases, besides strengthening the medical infrastructure with respect to its capability and capacity.

In the year 2010, Ministry of Health and Family Welfare launched a National Programme on Prevention and Management of Burn Injuries (NPPMBI), to ensure timely and adequate treatment in case of burn injuries and provide effective rehabilitative interventions if the disability has set in.

$\square$ In the year 2010, Ministry of Health and Family Welfare launched a National Programme for Health Care of Elderly (NPHCE), to address various health problems of elderly people. The main objectives were to establish a department of geriatrics centres in different regions of the country, to provide dedicated health facilities in district hospitals, community health centres, and primary health centres including sub-centres levels through state health society.

- In June 2011, Ministry of Health and Family Welfare launched Janani Sishu Suraksha Karyakaram (JSSK), with an initiative to make available completely free and cashless services to pregnant women, including normal deliveries and caesarean operations along with care for sick newborn, up to 30 days after birth in government health institutions in both rural and urban areas.

$\square$ In the year 2011, Ministry of health, Govt. of India launched Home Based New Borne Care (HBNC), as a scheme to incentivize accredited social health activities to provide Home based new borne care- to specified schedule up to 42 days of life.

$\square$ On $19^{\text {th }}$ March, 2012, under section 52 of the clinical establishment Act (CEA) under registration and regulations, 2010, which came into force on $1^{\text {st }}$ March, 2012- UNDER CENTRAL GOVERNMENT RULES, 2012. Under this National Council for Clinical Establishments (NCCE) was launched to prescribe minimum standards of facilities \& services by the clinical establishments.

Under the $12^{\text {th }}$ five-year plan (2012-17), the government of India launched a National Programme on Containment of Anti-Microbial Resistance (NPCAMR), with the aim to establish a laboratory based on AMR-Anti-Microbial Resistance, to strength infection control guidelines, to promote the 
rationale use of antibiotics and thus to generate awareness among providers and in the community about the rationale use of antibiotics.

$\square$ Under the 12 $12^{\text {th }}$ five-year plan (2012-17), the government of India, Ministry of Health and Family Welfare implemented as a National Rabies Control Programme (NRCP), with an objective to prevent transmission of rabies through canine (dog) rabies control and at the same time reducing human deaths due to rabies.

$\square$ Under the $12^{\text {th }}$ five-year plan (2012-17), the government of India implemented Programme for Prevention and Control of Leptospirosis (PPCL), with the aim to strengthen diagnosis laboratories for early diagnosis, patient's management facilities with inter-sectoral coordination to prevent and control Leptospirosis.

$\square$ Under the $12^{\text {th }}$ five-year plan (2012-17), the government of India implemented Inter-sector Coordination for Prevention and Control of Zoonotic Diseases (ICPCZD), with the aim to strengthen SSU under IDSP, train manpower development, sensitization of professionals in various sectors and IEC. This was to create awareness among community along with professional with respect to Zoonotic diseases.

$\square$ Under the $12^{\text {th }}$ five-year plan (2012-17), the government of India implemented National Programme for Prevention and Control of Viral Hepatitis, with the aim to provide laboratory out-break investigation of hepatitis through the establishment of the laboratory. And thus to develop technical material surveillance of viral hepatitis to generate awareness among the healthcare providers and in the community about waterborne and blood borne hepatitis.

In 2014-15, the Government of India, under the umbrella of NHM launched a National Oral Health Programme (NOHP), to improve the determinants of oral health in the country by providing comprehensive oral health care through synergistic, equality distributed general and oral health facilities and coordination with related sectors in public or private.

On $27^{\text {th }}$ March, 2014, the Directorate general health services under Government of India, with respect to THE pursuance of the amendment Act- Transplantation of human organs and tissues rules, 2014 launched the National Organ Transplant Programme (NOPT), to improve access to life transforming transplantation for needy citizens of our country by promoting deceased organ donation.

$\square$ On $25^{\text {th }}$ December, 2014 the Ministry of Health and Family Welfare launched Mission Indhradhasnush, with the aim of expanding immunization coverage to all children under the age of $2 \mathrm{yrs}$ as well as all pregnant women across India by 2020. It was against the seven vaccines preventable diseases named Diphtheria, Whooping Cough, Tetanus, Poliomyelitis, Tuberculosis, Measles and Hepatitis.

In the year 2014, the Government of India, under State Annual Action Plan-SAAP, launched National Ayush Mission (NAM), to provide and make available grants-aids with respect to naturopathy and yoga-based treatment in all rural areas, primary health centres, district hospitals and community health centres. 


\section{Statistical Status of Health-Care in India}

We know that health is defined under the ability to lead a socially and productive life. On the basis of this health indicators are variable, susceptible to direct measurement. Hence, Health measurement is framed in terms of illness, consequences of ill-health and factors that promote ill-health.

On the basis of these things, health indicators help to measure the extent to which the objective and targets of the programme are being attained. The selected health indicators are as follows:

(a) Crude birth rate (per 1,000 populations).

(b) Crude death rate (per 1,000 populations).

(c) Total fertility rate (per women).

(d) Maternal mortality rate (per 1,00,000 live births).

(e) Infant mortality rate (per 1,000 live births).

(f) Life expectancy at birth.

The status of these six inclusive heath indicators in India can be explained in details as follows:

(a) Crude Birth Rate (CBR), per 1,000 populations: CBR gives the annual no. of births during a year per 1,000 people of the population at mid-year. It is a dominant factor in determining the rate of population growth. It depends on the level of fertility and age structure of the population.

Table 1: Crude birth rate (per 1,000 populations)

\begin{tabular}{ccccccccc}
\hline Year & $\mathbf{1 9 5 1}$ & $\mathbf{1 9 8 1}$ & $\mathbf{1 9 9 1}$ & $\mathbf{2 0 0 1}$ & $\mathbf{2 0 1 1}$ & $\mathbf{2 0 1 5}$ & $\mathbf{2 0 1 6}$ & $\mathbf{2 0 1 7}$ \\
\hline Value & 40.8 & 33.9 & 29.5 & 25.4 & 21.8 & 19.3 & 19.0 & 18.8 \\
\hline
\end{tabular}

Source: 1. CSO-Data tables on Indian economy 2014-15; 2. Government of Indian-economic survey 2014-15; 3. Google survey on data's of the years in table.

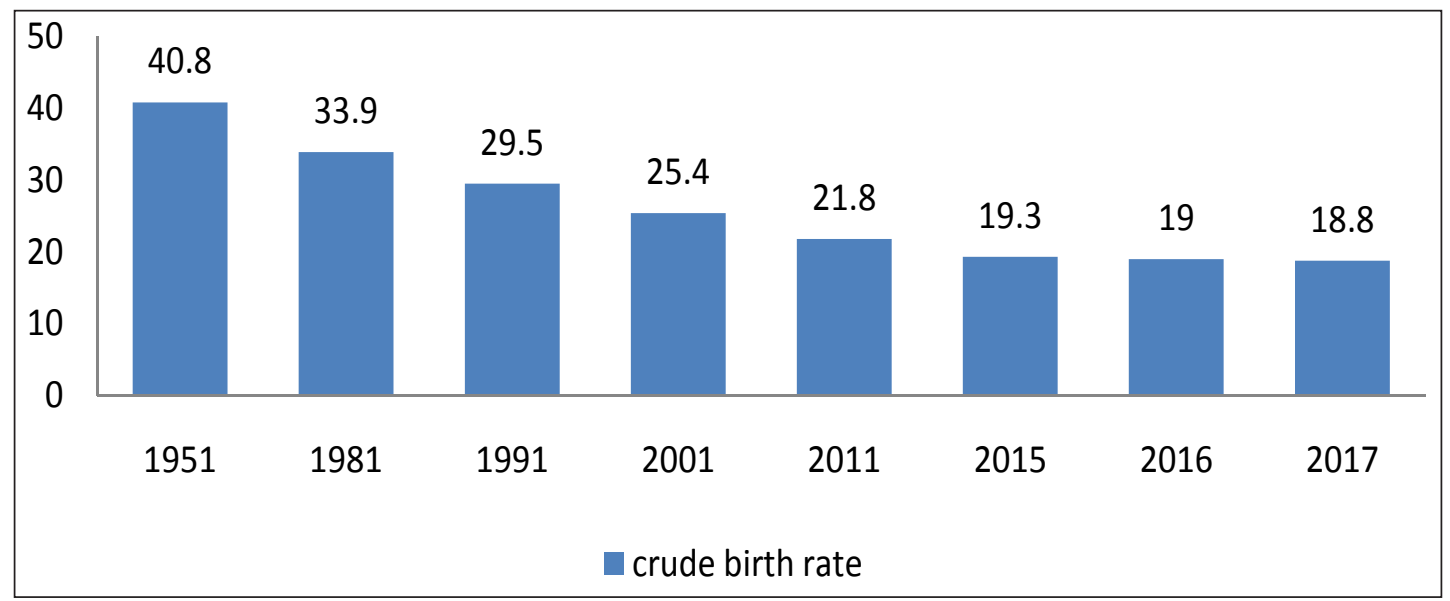

Fig. 1: Crude birth rate (per 1,000 populations) 
From the above table and graph, It is seen that INCLUSIVE HEALTH CARE FACILITY as per the CRUDE BIRTH RATE (CBR) has been declining over the years.

In 1951 CBR per 1,000 people of the population of India was 40.8, which decreased to 33.9 in 1981 , then to 29.5 in 1991.

In $20^{\text {th }}$ century also, CBR of India kept on declining, which is 25.4 in 2001, then to 21.8 in 2011. Further to $19.3,19 \& 18.8$ in 2015,2016 and 2017 respectively.

(b) Crude Death Rate (CDR), per 1,000 populations: CDR gives the annual no. of deaths during a year per 1,000 people of the population at mid-year. This is a rough indicator of the mortality situation in a country, accurately indicating the current mortality impact on the population growth.

Table 2: Crude death rate (per 1,000 populations)

\begin{tabular}{ccccccccc}
\hline Year & $\mathbf{1 9 5 1}$ & $\mathbf{1 9 8 1}$ & $\mathbf{1 9 9 1}$ & $\mathbf{2 0 0 1}$ & $\mathbf{2 0 1 1}$ & $\mathbf{2 0 1 5}$ & $\mathbf{2 0 1 6}$ & $\mathbf{2 0 1 7}$ \\
\hline Value & 25.1 & 12.5 & 9.8 & 8.74 & 7.48 & 7.3 & 7.31 & 7.33
\end{tabular}

Source: 1. CSO-Data tables on Indian economy 2014-15; 2. Government of Indian-economic survey 2014-15; 3. Google survey on data's of the years in table.

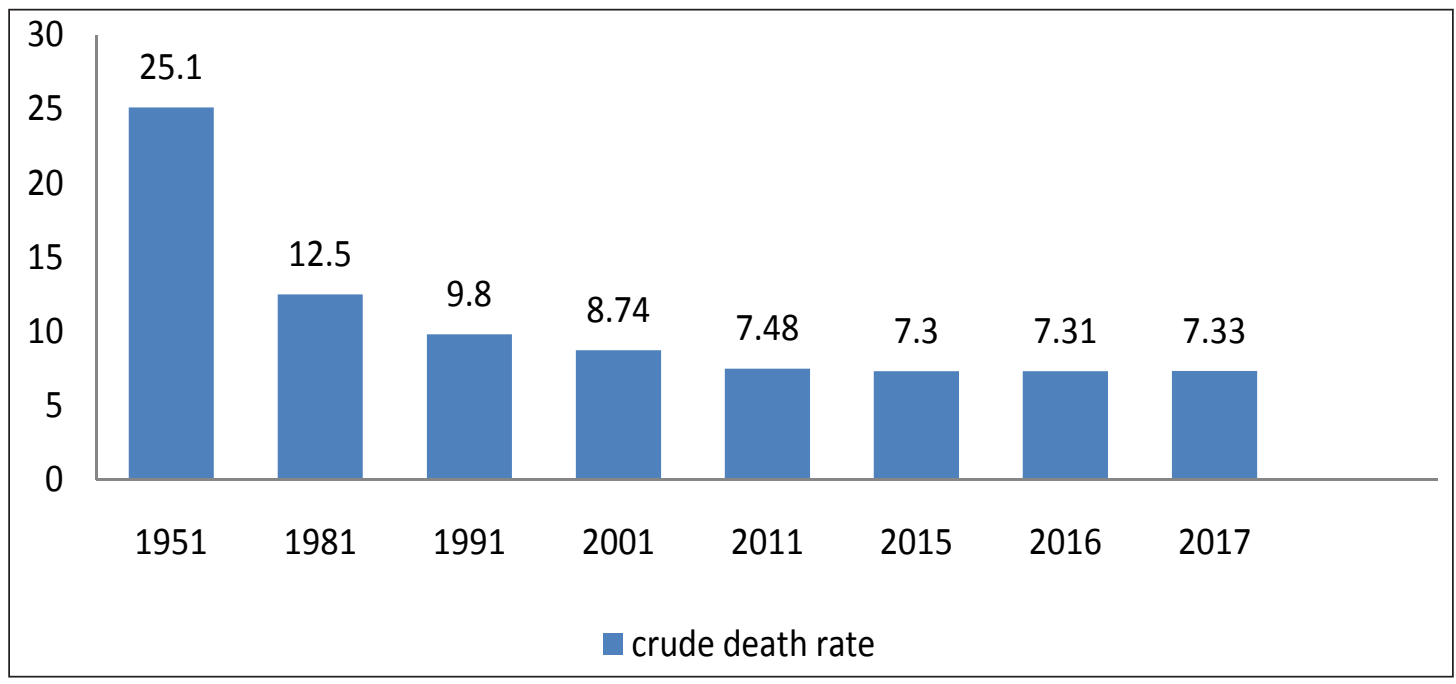

Fig. 2: Crude death rate (per 1,000 populations)

From the above table and graph, It is seen that INCLUSIVE HEALTH CARE FACILITY as per the CRUDE DEATH RATE (CDR) of India has always been declining, giving a positive impact on health structure of India's population-citizens.In 1951 CDR per 1,000 people of the population of India was 25.1, which decreased to 12.5 in 1981, then to 9.8 in 1991.

In $20^{\text {th }}$ century also, CDR of India kept on declining, which is 8.74 in 2001, then to 7.48 in 2011. Further to 7.3 in 2015 and 7.31 in 2016. But at the same time it also showed a minimum increase in the CDR of Indian citizens, in terms of 7.33 in 2017. 
(c) Total Fertility Rate (TFR), per women: TFR gives a figure for the average number of the children that would be born per woman; if all women lived to the end of their child-bearing years and bore children according to give fertility rate at each age.

Table 3: Total fertility rate (per women)

\begin{tabular}{ccccccccc}
\hline Year & $\mathbf{1 9 5 1}$ & $\mathbf{1 9 8 1}$ & $\mathbf{1 9 9 1}$ & $\mathbf{2 0 0 1}$ & $\mathbf{2 0 1 1}$ & $\mathbf{2 0 1 5}$ & $\mathbf{2 0 1 6}$ & $\mathbf{2 0 1 7}$ \\
\hline Value & 6 & 4.5 & 3.6 & 3.04 & 2.62 & 2.35 & 2.33 & 2.3 \\
\hline
\end{tabular}

Source: 1. CSO-Data tables on Indian economy 2014-15; 2. Government of Indian-economic survey 2014-15; 3. Google survey on data's of the years in table.

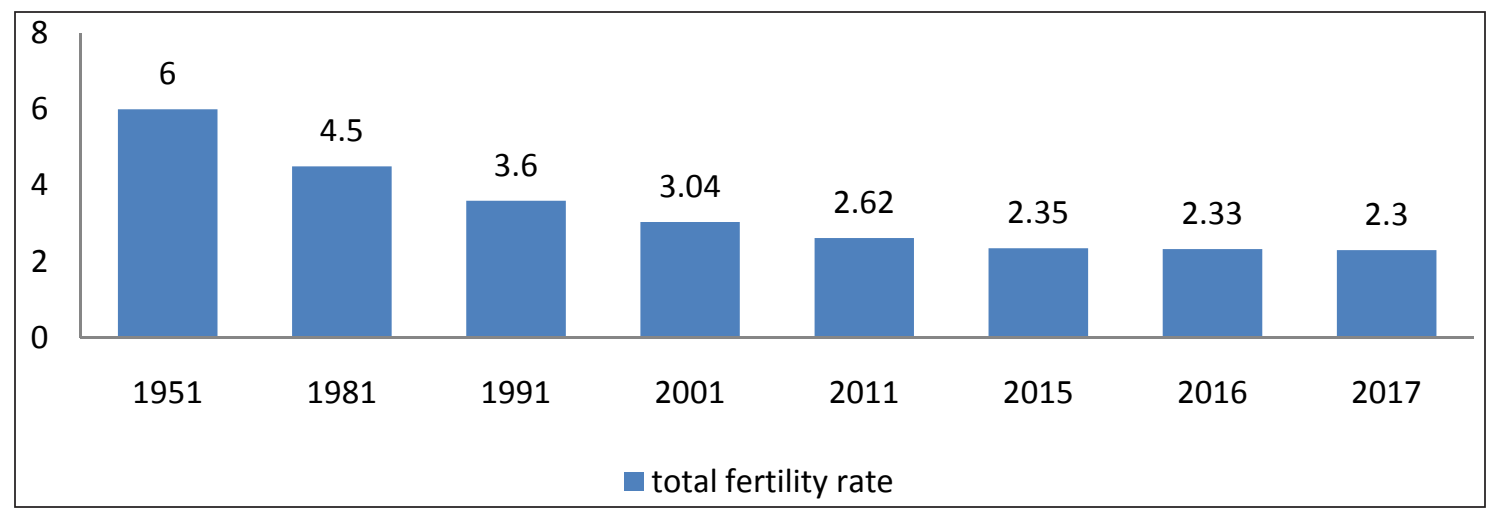

Fig. 3: Total fertility rate (per women)

From the above table and graph, It is seen that Inclusive Health Care Facility as per the Total Fertility Rate (TFR) of India has always been declining, giving a positive impact on the fertility situation of India's population-citizens. In 1951 the TFR per women of the population of India was 6, which decreased to 4.5 in 1981 , then to 3.6 in 1991 .

In $20^{\text {th }}$ century also, TFR of India kept on declining, which is 3.04 in 2001, then to 2.62 in 2011. Further to 2.35 in 2015 , then to 2.33 in 2016 and 2.3 in 2017.

(d) Maternal Mortality Rate (MMR), per 1,00,000 live births: MMR refers to annual number of female deaths per 1,00,000 live births, related to any cause of aggravation by pregnancy management excluding accidental or incidental causes. The MMR includes deaths during pregnancy, child birth or within 42 days of termination of pregnancy, irrespective of the duration and site of pregnancy, for a specified year.

Table 4: Maternal mortality rate (per 1,00,000 live births)

\begin{tabular}{|c|c|c|c|c|c|c|c|c|}
\hline Year & 1951 & 1981 & 1991 & 2001 & 2011 & 2015 & 2016 & 2017 \\
\hline Value & NA & NA & $\begin{array}{l}437 \text { (1992- } \\
93 \text { ) NFHS }\end{array}$ & $398(1997-98)$ & $212(2007-09)$ & $176(2010-12)$ & $167(2011-13)$ & $174(2012-15)$ \\
\hline
\end{tabular}

Source: 1. CSO-Data tables on Indian economy 2014-15; 2. Government of Indian-economic survey 2014-15; 3. Google survey on data's of the years in table. 


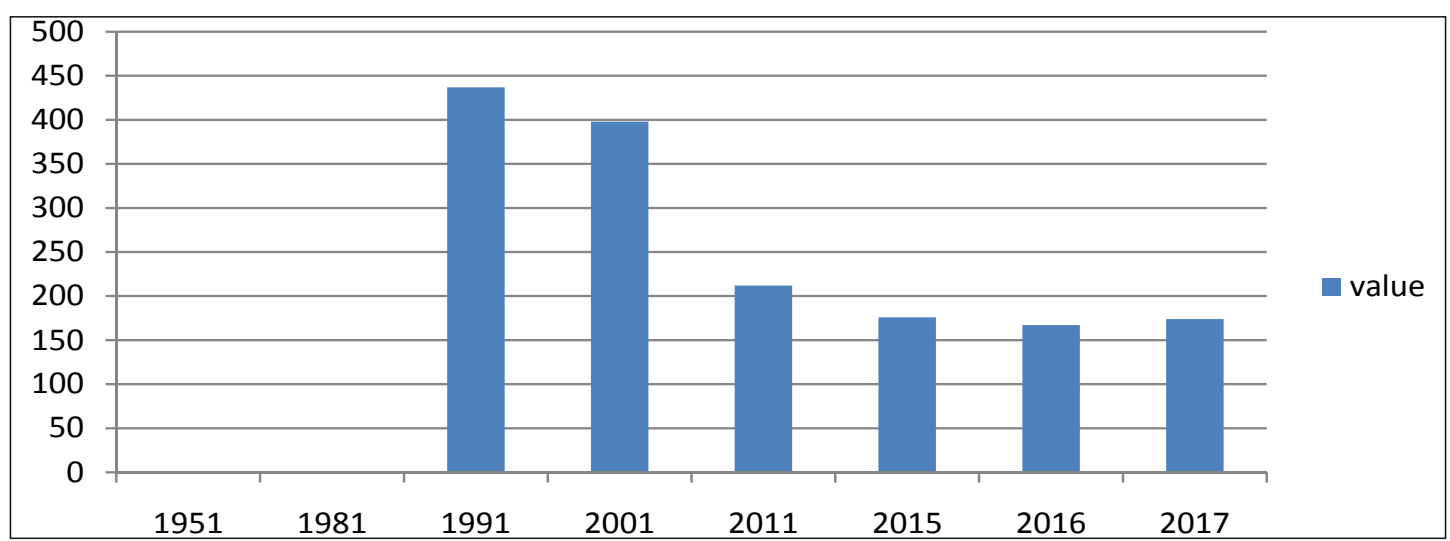

Fig. 4: Maternal mortality rate (per 1,00,000 live births)

From the above table and graph, It is seen that Inclusive Health Care Facility as per the Maternal Mortality Rate (MMR) of India has always been declining, giving a positive impact on the current mortality situation of India population-citizens.

In 1991, Maternal mortality rate (per 1,00,000 live births) was 437 , which decreased in the $20^{\text {th }}$ century as follows: MMR of India declined to 398 in 2001, then to 212 in 2011. Further to 176 in 2015, then to 167 in 2016 but in 2017 MMR increased to 174.

(e) Infant Mortality Rate (IMR), per 1,000 live births: IMR gives the number of deaths of infants under one year old in given year 1,000 live births in the same year, including is the total death rate and death by sex, male and female. This rate is usually used as an indicator of the level of health in a country.

Table 5: Infant mortality rate (per 1,000 live births)

\begin{tabular}{cccccccccc}
\hline Year & $\mathbf{1 9 5 1 - 6 1}$ & $\mathbf{1 9 8 1}$ & $\mathbf{1 9 9 1}$ & $\mathbf{2 0 0 1}$ & $\mathbf{2 0 1 1}$ & $\mathbf{2 0 1 3}$ & $\mathbf{2 0 1 5}$ & $\mathbf{2 0 1 6}$ & $\mathbf{2 0 1 7}$ \\
\hline Value & 146 & 110 & 80 & 63.19 & 43.60 & 40 & 37.81 & 36.6 & 35.4 \\
\hline
\end{tabular}

Source: 1. CSO-Data tables on Indian economy 2014-15; 2. Government of Indian-economic survey 2014-15; 3. Google survey on data's of the years in table.

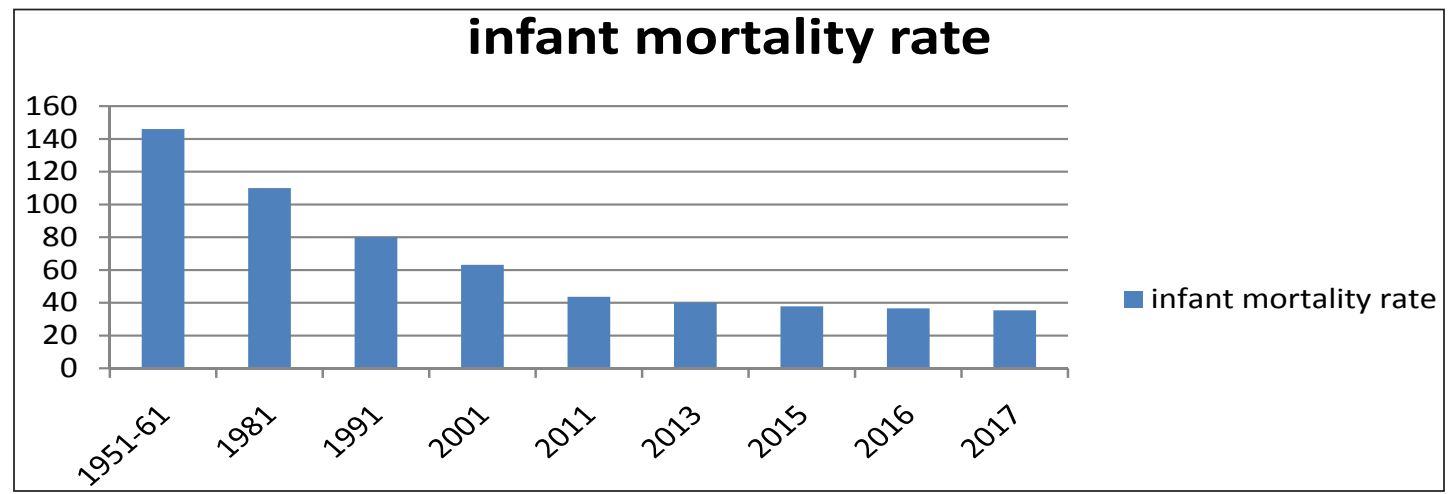

Fig. 5: Infant mortality rate (per 1,000 live births) 
From the above table and graph, It is seen that Inclusive Health Care Facility as per the Infant Mortality Rate -per 1,000 live births (IMR) of India has always been declining, giving a positive impact on the current mortality situation of India population-citizens.

In 1951 IMR of the population of India was 146, which decreased to 110 in 1981, then to 80 in 1991.

In $20^{\text {th }}$ century also, IMR of India kept on declining, which is 63.19 in 2001, then to 43.60 in 2011. Further to 40 in 2013, then to 37.81 in 2015, then to 36.6 in 2016 and 35.4 in 2017.

(f) Life Expectancy at Birth: Life expectancy at birth contains the average number of years to be lived by a group of people born in the same, if mortality at each age remains constant in the future. It is a measure of overall quantity of life in a country and summarizes the mortality at all ages.

Table 6: Life expectancy at birth

\begin{tabular}{ccccccccc}
\hline Year & $\mathbf{1 9 5 1}$ & $\mathbf{1 9 8 1}$ & $\mathbf{1 9 9 1}$ & $\mathbf{2 0 0 1}$ & $\mathbf{2 0 1 1}$ & $\mathbf{2 0 1 5}$ & $\mathbf{2 0 1 6}$ & $\mathbf{2 0 1 7}$ \\
\hline Value & N.A & 55.5 & 59.4 & 62.86 & 66.8 & 68.3 & 68.56 & 68.80 \\
\hline
\end{tabular}

Source: 1. CSO-Data tables on Indian economy 2014-15; 2. Government of Indian-economic survey 2014-15; 3. Google survey on data's of the years in table.

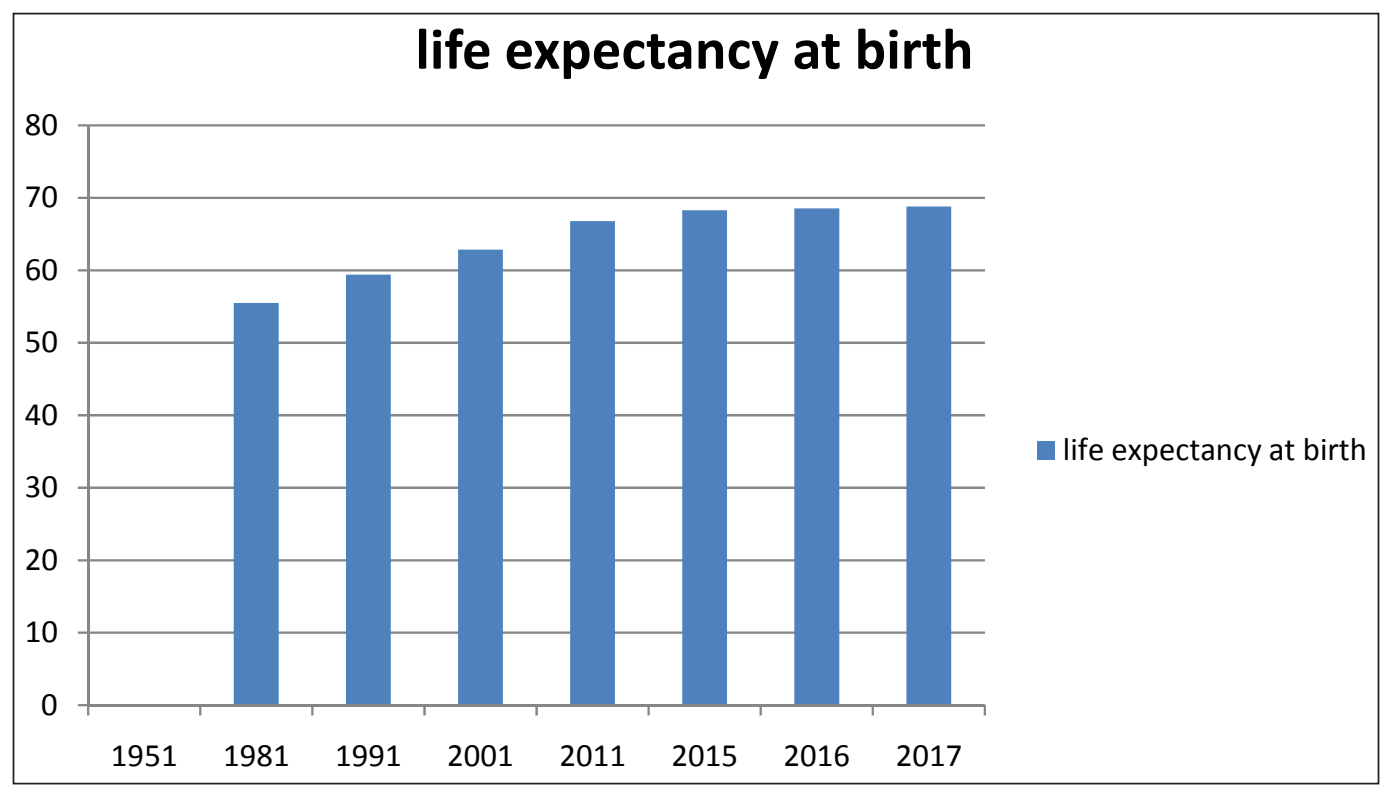

Fig. 6: Life expectancy at birth

From the above table and graph, It is seen that Inclusive Health Care Facility as per the Life Expectancy At Birth of India has always been increasing over the years, giving a positive impact on the health situation of India's population-citizens.

In 1981 life expectancy at birth of the population of India was 55.5, which increased to 59.4 in 1991. In $20^{\text {th }}$ century also, it kept on increasing as follows, that is it went up to 62.86 in 2001 , then to 66.8 in 2011. Further to 68.3 in 2015, then to 68.56 in 2016 and 68.80 in 2017. 
In this way, it is proved that the development of the healthcare sector is one of prime importance in development strategy. Under the health system in India, which is a mixture of the public and private sectors inclusive health-care system is very-very important. With respect to this, it is seen that the India has developed a well-structured three-tier public health infrastructure, comprising community health centres (CHCs), primary health centres (PHCs) and sub-centres spread across rural and semi-urban areas as well as medical care comprising multi-speciality hospitals and medical colleges located exclusively in urban areas. The private sector plays a dominant role in providing health services in India. It is estimated that around $70 \%$ of all hospitals and $37 \%$ of all total hospital beds in the country are in the private sectors. The growth and achievements of health facilities in India are very significant, which can be analyzed as follows:

Table 7: Expansion of health services in India, (1951 to 2015)

\begin{tabular}{lcc}
\hline Types of health services & $\mathbf{1 9 5 0 - 5 1}$ & $\mathbf{2 0 1 4 - 1 5}$ \\
\hline Medical colleges & 28 & 398 \\
Dental colleges & N.A & 305 \\
Number of government hospitals & 2,690 & 20,300 \\
Number of dispensaries (AYUSH) & 6,510 & 26,100 \\
Number of health centres & 725 & 1.83 lakh \\
Number of government hospitals beds & 1.17 lakh & 6.76 lakh \\
Number of doctors (allopathic doctors \& dental surgeons) & 61,800 & 10.93 lakh \\
Number of nurses & 18,000 & 25.6 lakh \\
Number of registered doctors per 1,00,000 people & 17 & 76 \\
\hline
\end{tabular}

Source: Ministry of health \& family welfare, central bureau of health intelligence, national health profile, 2015.

From the above table, analysis of Inclusive Health Care Facility as per the Expansion of Health Services In India, (1951 TO 2015) of India can be done bringing forward its positive impact on the India's population-citizens.

It is seen that, in 1950-51 number of Medical colleges were only 28, which increased to 398 in 2014-15. Similarly, the number of dental colleges increased to 305 in 2014-15. Number of dispensaries (AYUSH) also increased from 2,690 in 1950-51 to 20,300 in 2014-15.

Related to it Number of health centres, Number of government hospitals beds, Number of doctors (allopathic doctors \& dental surgeons), Number of nurses and Number of registered doctors (per 1,00,000 people) increased from 725, 1.17 lakh, 61,800, 18,000 and 17 in 1950-51 to 1.83 lakh, 7.76 lakh, 10.93 lakh, 25.6 lakh and respectively.

In this way statistical analysis of inclusive health-care in India shows how progressively and positively health care facilities have developed in India. It is seen from this analysis that, it is by following and bringing forward inclusive growth strategy to achieve sustainable socio-economic development in India, with respect to health facilities for all its citizens and others to residing in India. Thus, it is clear from these above figures and tables that the number of health-care services established and people receiving these services under inclusive health-care is constantly growing in India. 


\section{Need and Importance of Inclusive Health-Care in India}

From the statistical data's and figures above, we can see that there is a great need for inclusive health care in India, raising its importance with respect to evaluations followed by analysis of Indian health care used to evaluate the process of health care, health care structures and/or outcomes of health care services in India. This evaluation of the quality of health care should always be based on:

$\square$ Hospital quality.

$\square$ Health plan quality.

$\square$ Physician quality.

$\square$ Quality of other health professionals.

$\square$ Patients' experiences.

So, accordingly to enhance the India's health-care system on the above mentioned basis, inclusive healthcare plans and policies are very needed to be implemented in India, to improve all the above mentioned health-care qualities in Indian systems of health-care service delivery at its level best. The Need Of Inclusive Health-Care System can be analyzed through following factors:

$\square$ To promote collaboration of general and special health-care institutions of India for delivering continuous health-care services to all patients-removing any discrimination between wealthy and low-income citizens of India. In this way these services of Indian health-care, as a continuous process of inclusive health care, will help in economic welfare followed by prosperity for both India and its citizens, with human resource development.

$\square$ For strengthening the participation of all health-care resources of India like health-care institutions, doctors, its staffs, pharmacies, etc. for delivering health-care services in all areas of India. This will help in the delivery of health-care services on a sustainable basis, following the principles of inclusion, reducing and removing the inequality of health-care service delivery in rural and urban areas of our country.

$\square$ To restructure the Indian health-care service delivery policies and programmes with well constructed individualized health-care plans following the principles of inclusion, for improving the maintenance and management of health-care structure of India. Respond to these policies will help to remove the diversity in health-care service delivery in various sections, sectors etc of particular localities, answering and solving the patients' health-care needs and demands in India.

$\square$ To provide integrated health-care service delivery by the development of training programmes and support system to all care resources to India. This will help in developing and improving the potential of the Indian health-care system by collecting, giving and using the correct information on health-care services with respect to its process, its uses and problems involved, followed by how the problems can be solved.

$\square$ To create appropriate and accessible curriculum for providing correct \& full information to all Indian citizens about health-care systems \& its accessible payment mechanism like health insurance policies, available in India. This can help the Indian patients' to understand and know that where they can get specific solution of their health problem answering in what manner it afforded to them by trusted providers. 
As, we see from the study made above that, as the functionality and adoption of connected health increases potential of the health system. This shows the IMPORTANCE OF INCLUSIVE HEALTH-CARE IN INDIA, with increased benefits and the creation of greater levels of value in India health-care system. Thus, the following factors show the importance of inclusive health care in India needed improving its health-care systems quality. These are as follows:

$\square$ To improve the health-care efficiency with IT adoption: Healthcare IT adoption and Health Information Exchange (HIE) can take place through planning, construction and use of digital infrastructure in the health-care systems of India. This is important, as it can help in following things:

$\odot$ Reduction in duplicity in medical testing,

$\odot$ Quicker access to vital patient information and

$\odot$ Reduction of various health-care service delivery costs.

$\square$ To share knowledge through Health information exchange: By exchanging the various captured health information like alerts related to drug interactions, greater use of evidence with respect to health-care protocols, inventions of new capabilities in health-care management system etc. We can deepen the connection between clinicians, across administrative groups and with patients. This is a very important way, to share health-care knowledge and information followed by improvement in health-care quality of the Indian health-care system by:

○ Reducing medical test errors,

$\odot$ Increase the preventive potentials of health-care and

$\odot$ Low cost care for chronic conditions.

$\square$ To transform health-care systems with Insight driven healthcare: By Advanced analysis and evaluation of data's related to Indian health-care delivery systems. Its importance arises, as through this we can check and improve the efficiency needed for delivery of inclusive health-care services, in following manner:

$\odot$ Implementation of Cooperative medical decision-making methods,

$\odot$ Population health management,

$\odot \quad$ Creation of new health-care delivery models, including patient self-management and

$\odot$ Better health-care coordination among health-care resources.

There are three milestones which show the importance of inclusive health-care and above five factors answers the question why inclusive health is needed in India, on the journey to connect health-care system from all corners. So, accordingly on the basis of the above study, to improve the potential of health-care present in India, adoption of the inclusive health-care system is very important and necessary in India.

\section{Challenges Faced by India to Implement Inclusive Health-Care}

The medical devices sector is the smallest percentage piece of India's health-care pie. However, it is one of the fastest growing sectors in the country like insurance marketplace. Till date, the industry has faced a number of regulatory challenges which has prevented its growth and development in India. These are as follows: 
Inequality of services under rural and urban medical centers: It is seen that still in India, the incidence of the diseases is steadily increasing and mostly vast majority of rural and poor patients still suffer from infectious diseases. This is because the urban areas of India have numerous government plus private hospitals and clinics which provide quality health care, with better doctors, access to preventive medicines, but most of the rural areas of India lack these facilities. This rises to severe inequalities in health-care infrastructure between urban and rural areas with respect to all major health indicators.

Lack of Effective payment mechanism: The Indian government has often facilitated its citizens with safety net health insurance programmes, which is designed for people to pay upfront cash for medical treatments. There are also few private additional plans, which sell private health insurance to public. But still the key-drivers of India's health-care payment are often high out-pocketing expenditure, which are mostly straight forward cash payments. This shows that in India health insurance facilities are only available for urban, middle and high income populations. Thus, in having low penetration of insurance and other payment mechanisms as today also in Indian pay through cash-open pockets for various health care services.

$\square$ Lack of Basic primary health care and its infrastructure: Indian population faces the growing needs to address the basic health concerns in the areas of HIV, malaria, tuberculosis, diarrhea etc. And surveys show that only about 30 percent of total budget are in healthcare. The problem related to these primary health care services is that India lacks health infrastructure, rural clinics, health IT systems, etc. which often lead to dual disease burden for Indian.

$\square$ Low growth of pharmaceutical sectors in terms of both quality and quantity: Though development of pharmaceutical industries is rising day by day in India, still it is seen that mostly this market is composed of low-cost with respect to low-quality drugs. Because of which it does not suit the primary health care of almost all the citizens' mostly in rural areas and in building clinical health efficiency in India.

Underdevelopment of medical device sectors: In India, the smallest piece of health-care pie is medical device sector related to the adoption of IT healthcare, exchange of health information in all the areas of India and population health management and health-care delivery systems.

\section{Measures which Acts as a Necessity for Implementing Inclusive Growth in India}

Expenditures on health are considered as an investment in human resources, contributing to productivity of human resources of the country, increasing development of the country progressively and successfully. These measures can be explained broadly under these two following heads:

$\square$ Measures to make inclusive health-care a reality and advanced strategy of development in India: The labour productivity hypothesis asserts that individuals who are healthier have higher return to labour input. Thus, under this following measures should be adopted:

- Promotion of health enhancing techniques with potentials with respect to patients' needs: Under this the most important thing is to understand the patient's needs and wants with respect to their health-care. Again steps should be taken, to give full information to the patient's, that a general plus specific solution is always available to them at an affordable price by a trusted provider, who is approved by Indian government. Thus, under this measure, 
to implement inclusive health-care in India, in these above mentioned ways, efforts should be made to substantially remove the difference between health-care services delivered to wealthy and low-income group of people-citizens of India.

$\odot$ Engagement in delivering health-care services to all with the help of community bonding: This measures main objective should be to respond to the diversity of patients, health-care demand in a given locality, by creation of community trust through every local community bonding in one unit. So, that one can help the other in needs of health-care following inclusive health-care delivery system in India. So, here community engagement services through this trust creation should be analyzed, introduced and implemented, to sharpen patient's healthneeds with awareness of health-facilities present. At the same time, it should ensure successful acceptance of health-care delivery solutions with respect to both pre underprivileged and economically well-off patients, as per problems faced by them.

$\odot \quad$ Health-care delivery should be continuously provided as per both wants and need of patient's: Here under the inclusive health-care system, the Indian teams of medical devices such as doctors, medical staffs etc, should find easy to continuously engage themselves to help the customers with team development, which may be affordable as well as suitable as per local needs and could be used on a regular basis. Thus, here major objective should be to collect relevant information and insights about the uses of medical devices like institutions, its staffs, community members and pharmacies in the work of inclusive health-care systems. This should be done, with respect to the fact as to how they are used for solving health issue problems and also to bring forward the fact that what is the difficulty in using them. So, that solution can be developed to suit the health needs of various scattered populations of India.

$\odot$ Technological advancement with IT innovation in the medical sector of India: This measures main objective should be the innovation of IT facilities, heading towards technological advancement in the field of the inclusive health-care system of India. So, that full information about the medical facilities and technology-enabled health-care facilities can be provided, responding to the diversity of patients health-care demand in a given locality. Under this fundamental ways of IT and technological advancement should be developed through societal values and policies taken in for development of the health enhancing potential of all medical, institutional areas of India, to develop all the clinical health-care systems of India.

Measures to support inclusive health-care as a developmental strategy in India: The incentive effects are borne of the theoretical literature and individuals who are healthier and have greater life expectancy. This will have the incentives to invest in all other sectors with heir productive capacity, as the time horizon over which returns can be earned is extended. Thus, Under this following measures should be adopted:

$\odot$ Medical sector human resource development: Under inclusive health-care delivery innovations should be enabled to use same human resources of the medical sector, in all the areas of India, even at a low cost. So, accordingly the founders should take measures to set-up a model, which should/could give incentives to attract and motivate the medical based human resources like doctors, nurses, other medical staffs etc; to work in rural and semi-urban areas, along with urban areas. Thus, in this way it should focus on leverage of intrinsic motivation of health-professionals, to work in semi-urban and rural areas, along 
with hospitalization giving basic health-care delivery and treatments. It should be given at best level through disruptive innovation perspectives of health-care delivery without any discrimination in areas and patients.

○ Strategic development in health-care delivery: Partnership between medical technology innovations and adequate medical personnel are two very important internal resources for strategic development. So, it is needed in India to develop and support inclusive health-care delivery to reach the rural areas at low cost. So, under this measure Indian government should aim at sustaining quick and effective acquisition of these internal resources, by using extensive network of strategic partners.

- Economies of scale in health-care delivery: It is still seen that in most of areas Indian health organization, exploit scale benefit of providing quality-health treatment. Thus, under this measure economics of scale Assembly line model should be developed, to improve quality of health service delivery, reducing its cost from all sides by enhancing doctors' skill and minimizing errors in this field of health-care. In this way, implementation of inclusive healthcare can achieve profitability and sustainability primarily through the effects of economies of scale under health-care delivery in India.

$\odot$ Inclusive health-care through Cross-Subsidization: Inclusive health-care can be implemented perfectly by cross- subsidization modal. This can take place by promoting organizational mechanism with respect to which affluent consumers pay a relatively higher price for medical product and services compared to lower price paid by underprivileged sections of society, for the same product or services. Under this, all hospitals provide the same medical facilities for all patients, reducing the access gap and ensuring a suitable mix of wealthy and low income patients. One of the best ways to do it is to periodically rotate the services of medical resources like doctors between paid and free sections patients admitted in hospitals. Thus, with the help of cross- subsidization, inclusive health-care services can be achieved in ensuring a suitable mix of wealthy and low-income patients by reducing the gap of health-care delivery between them.

Thus, if these measures are adopted it makes a very important contribution to economic progress of the country. As healthy population live longer, are more productive and save more. So, accordingly, health status contributes quality health services for its people.

\section{CONCLUSION}

We know that health care delivery is expensive with respect to the wide deployment of specialized knowledge and labour in most phases of care and treatment. But, under inclusive health-care facilitiesHealth as a human right should provide a useful breakdown of different aspects of rights to health, with respect to the relationship between health and following development systems:

Inclusive rights,

Freedom from non-consensual medical treatment,

$\square$ Entitlements to prevention, treatment and control of diseases, by giving access to essential medicines, health related education, timely services etc. 
Non-discrimination with respect to Accessibility and

Acceptability and quality of services.

So, accordingly human rights advocate that organisations or systems that are embarking on the connected health journey should begin with a clear assessment of their own health care. It should be with respect to health facilities as per patients' needs as well as medical technology innovation, leading to the development of Human resources for health delivery in both rural and urban areas of the Indian economy. And most important of all, the medical professionals or human resources for health (HRHs) should be provided with same resources, but at lower expenses with respect to developmental reasons other than financial incentives to offer their services both efficiently and successfully under inclusive health care facilities in India.

\section{REFERENCES}

1. Balarajam, Y., Selvaraj, S. and Subramanian, S. 2011. "Health care and equity in India", available on www.ncbi.nlm.nih.gov

2. Bandari, L. and Dutta, S. 2007. "Health infrastructure in rural India", India Infrastructure report;2007; available on www.ncbi.nlm.nih.gov

3. Barik, D. and Thorat, A. 2015. "Issue of unequal Access to public health in India"; available on www. ncbi.nlm.nih.gov

4. Das, J., Hammer, J. and Leonard, K. 2008. "The quality of medical advice in low-income countries"; Published in J Econ Perspect., 22(2): 93-114.

5. Desai, S.B., Dubey, A., Joshi, B.L., Sen, M., Sheriff, A. and Vanneman, R. 2010. "Human Development in India: challenges for a society in Transaction"; Published by Oxford University Press, New Delhi.

6. Economic times. 2018. "India $145^{\text {th }}$ among 195 countries in health care access, quality". Available on https://www.economictimes.indiatimes.com

7. Iyengar, S. and Dholakia, R.H. 2012. "Access of the rural poor to primary health care in India. Rev. Market Integr., 4: 77-109.

8. Indian Pediatrics. 2018. "Delivering quality health care in India: Beginning of improvement Journey"; available on https://indianpediatrics.net.

9. Jat, T.R., Ng, N. and san Sebastian, M. 2011. "Factor affecting the use of material health services in Madhya Pradesh state of India: A multilevel analysis", published in Int. J. equity Health 2011,dec 5; available on www.ncbi.nlm.nih.gov

10. Jawahar, S.K. 2007. "Healthcare scenario in India", published in ICU Management and practice, ICU volume 6-Issue 4-winter 2006/2007, available on https://healthmanagement.org

11. Krishna, R. 2017. "Seven charts that show why India's health care system needs and overhaul"; available on https://www.livemint.com 
12. Kumar, R. 2012. "Way ahead in medical education reforms, published in academic institutionalization of community health services"; J. Family Med. Prim. Care, 1: 9-10.

13. Mohanan, M., Hay, K. and Mor, N. 2016. “Quality of health care in India: challenges, priorities and the road ahead", available on https://www.healthaffairs.org

14. Planning commission of India-12 $2^{\text {th }}$ five year plan (2012-2017): "Faster, more inclusive and sustainable growth", e social sciences-2013, available on https://econpapers.repec.org

15. Report of steering committee of health. 2012. available on https://www.planningcommission.nic.in.pdf

16. Saha, U.G. and Saha, K.B. 2010. "A trend in women's health in India- what has achieved and what can be done”, Rural remote health, 2010; 10; 1260. Available on https:/www.ncbi.nlm.nih.gov

17. Sharma, R.K. and Dhawan, S. 1986. "Health problems of rural women"; published in Popul perspect Issues-1986; pp: 18-25.

18. Singh, S. and Badaya, S. 2014. "Health care in rural India: A lack between need and feed"; published in south Asian journal of cancer, 2014, April-June; 3(2): 143-144. 
